\title{
The damage done by the war on opioids: the pendulum has swung too far
}

\author{
This article was published in the following Dove Press journal: \\ Journal of Pain Research \\ 12 May 2014 \\ Number of times this article has been viewed
}

\author{
Timothy J Atkinson' \\ Michael E Schatman ${ }^{2}$ \\ Jeffrey Fudin ${ }^{1,3-5}$ \\ 'PGY2 Pain and Palliative Care \\ Pharmacy Residency, Stratton \\ VA Medical Center, Albany, NY, \\ ${ }^{2}$ Foundation for Ethics in Pain Care, \\ Bellevue, WA, ${ }^{3}$ School of Pharmacy, \\ University of Connecticut, Storrs, CT, \\ ${ }^{4}$ Western New England University \\ College of Pharmacy, Springfield, MA, \\ ${ }^{5}$ Buffalo College of Pharmacy, State \\ University of New York, Buffalo, \\ NY, USA
}

In the United States, patterns of opioid use for the management of pain have drastically changed over the past 30 years. In the 1980s, the American pain medicine landscape was characterized by opiophobia, the fear to prescribe opioids. Around the turn of the millennium, however, we witnessed a fairly rapid shift to opiophilia, or the "overprescribing" of opioids. The ubiquitous undertreatment of pain was the catalyst for clinicians and pain societies to successfully lobby for increased use of opioids for all pain types, including non-cancer pain. The approval of new standards for pain management incorporating pain as the "fifth vital sign" by the Joint Commission on Accreditation of Healthcare Organizations (JCAHO $)^{1}$ seemingly fueled this increase in opioid prescription. From 1991-2009, prescriptions for opioid analgesics tripled, with emergency department visits related to non-medical use of prescription opioid overdoses doubling from 2005-2009. ${ }^{2}$ In 2010, accidental overdose deaths associated with opioids increased for the eleventh consecutive year, highlighting the drastic shift in opioid use. ${ }^{3}$ The figurative pendulum began to swing toward opiophobia following the publication of data that demonstrated that the risk of addiction associated with chronic opioid use was likely underestimated. ${ }^{4}$ Guidelines for the use of controlled substances released by the Federation of State Medical Boards of the US in 1998 reflected this change in attitude. ${ }^{5}$ At present, there is a general consensus that opioids are over-prescribed and education among health care providers is sorely lacking, with considerable debate on how to appropriately address the issue not yet resulting in a balance between treating legitimate pain patients, and mitigating abuse, overdoses, and related deaths. In this environment, physicians and non-physician prescribers, health systems, regulatory agencies, and insurers are seeking tangible targets for intervention.

The US Food and Drug Administration (FDA) has been criticized for its Risk Evaluation and Mitigation Strategy (REMS) program, which some believe creates burdensome barriers for appropriate opioid prescription. ${ }^{6}$ However, the agency's recent response to a strongly anti-opioid organization's petition to further impede opioid prescription was encouraging. ${ }^{7}$ The petition requested three changes to the indications for opioid use: 1) striking the term "moderate" from opioid labeling for chronic non-cancer pain, 2) adding a maximum daily dose equivalent of $100 \mathrm{mg}$ morphine for non-cancer pain, and 3) adding a maximum duration of 90 days for continuous use for non-cancer pain. The FDA responded by stating that, "When prescribed and used properly, opioids can effectively manage pain and alleviate suffering - clearly a public health priority", and "FDA knows of no physiological or pharmacological basis 
upon which to differentiate the treatment of chronic pain in a cancer setting or patient from the treatment of chronic pain in the absence of cancer. FDA therefore declines to make a distinction between cancer and non-cancer pain in opioid labeling." "The limitations for maximum daily dose or duration of treatment were denied for lack of scientific evidence. The FDA agreed to change the term "moderate" because it is moving away from severity classifications (mild, moderate, severe) to focus prescribers' attention on an individual's needs, accounting for the serious risks of opioid therapy and lack of alternative analgesic options in certain clinical scenarios. The FDA received over 1,900 comments regarding the petition, most of which opposed the petitioners' recommendations; among them were comments from chronic pain patients, clinicians, and professional societies, with professional societies expressing concern for the lack of evidence supporting these changes and the "one size fits all approach" instead of individualized care. ${ }^{7}$

Despite the petition being denied, the proposed changes have crept into policy and practice within various health systems, prescriber networks, insurance plans, and community pharmacy retail chains. For some, this reflects the desperation for potential interventions to address the opioid problem, while for others it has provided the justification to deny care to legitimate pain patients requiring time and valuable health care resources to adequately treat and monitor. Meanwhile, third party payers continue to deny or severely limit adjunctive non-medication options such as physical therapy, acupuncture, chiropractic care, exercise programs, etc. The treatment for most types of chronic pain with the highest evidence-basis and the lowest level of iatrogeneses - interdisciplinary pain management programs - is facing extinction (outside of the Veterans Administration system) in the US, as insurers refuse to pay for them (despite strong empirical evidence of costeffectiveness as well as clinical efficacy). ${ }^{8}$ Ironically, when pharmacotherapy becomes the complete therapeutic focus, those groups at greatest risk of abuse and diversion are the very same cohort of patients denied expensive extended release therapies that are more often available in abuse deterrent formulations. ${ }^{9,10}$ Just as the risk of opioid treatment was underestimated previously, today we see adverse outcomes or addiction being used to illegitimately deny access to large groups of patients who struggle daily with chronic pain. The Institute of Medicine's 2011 report Relieving Pain in America, estimated that 100 million Americans suffer from chronic pain. ${ }^{11}$ Treatment of pain costs the US approximately $\$ 635$ billion per year, which is more than heart disease, cancer, and diabetes combined. ${ }^{11}$ We suggest that the increase in opioid prescribing may in fact be the result of concerned clinicians attempting to treat a legitimate and widespread public health problem. Today, it is widely accepted that opioid prescribing has become excessive, necessitating a paradigm change resulting in an improved general approach to pain management.

A paradigm shift is critical to return individualized patient care to the central focus and move toward a more balanced approach to pain management incorporating lessons learned over the past 30 years. Any efforts toward equilibrium are currently being compromised by media sensationalism, the antagonistic approach of regulatory agencies, and third party payers' refusal to cover safer pain medications. Recently, public pressure in response to media sensationalism, neuromythology, and mischaracterization of pain patients as drug addicts has even deterred some prescribers from treating pain patients that they have successfully treated for years without problems of drug aberrancy. Similarly, regulatory crackdown and fear of expensive lawsuits has resulted in major retail pharmacy chains turning away pain patients, thereby forcing them to "crawl" from pharmacy to pharmacy, hoping that their prescriptions will be filled. ${ }^{12}$ This enforcement-based approach to reduce inappropriate use of opioids makes no distinction between pain patients and addicts. Unfortunately, this approach has been consistent with the US drug enforcement policy since the Harrison Act of 1914 through to the "war on opioids" today. Throughout US history, any effort to reduce the demand for opioids by educating prescribers, increasing monitoring, and treating addicts has received insufficient support. ${ }^{13,14}$ In addition, third party payers consider only cost when considering confirmation or validity testing for urine drug screens, abuse deterrent opioid formulations, or frequency of clinician monitoring and follow-up. ${ }^{15}$ These measures are critical to weeding out abusers from legitimate pain patients, and are clearly cost-effective measures for reducing unnecessary long-term dispensing of large supplies of opioids to individuals interested in diversion or abuse.

While estimates of opioid misuse, abuse, and addiction vary in patients with chronic pain, they clearly represent only a small portion of this unfortunate population. ${ }^{16,17}$ Why should patients with chronic pain who are prescribed necessary opioids for legitimate medical purposes endure the wrath of policy changes and resultant untreated pain due to criminality of others, or because clinicians are undertrained in identifying risks and addressing those risks? These questions certainly raise ethical concerns.

From practical and ethical perspectives, the keys to reducing abuse, diversion, overdoses, and accidental deaths 
associated with prescription opioid use are neither state and federal regulatory sanctions and intimidation, nor media histrionics aimed at selling more press. Rather, the keys to reducing aberrancy while continuing to safeguard access to these medications for the subpopulation of chronic pain sufferers that can benefit from them involve better risk mitigation. Regulatory agencies and the media seem to believe that risk mitigation is their responsibility, when, in order to protect patient autonomy, it should rest primarily in the hands of the once sacred provider-patient dyad. Very few physicians are "bad players" when it comes to opioid prescription, ie, engaging in frank maleficent behavior (eg, running "pill mills"). Indeed, few would disagree with the responsibility of regulatory agencies to intercede aggressively in such cases. Given that some physicians can perhaps be accused of being remiss in their opioid prescribing practices by not utilizing the tools that they have at their disposal to mitigate risk, including taking detailed medical histories, utilizing brief screening measures such as the Screener and Opioid Assessment for Patients with Pain (SOAPP) ${ }^{18}$ or the Pain Medication Questionnaire (PMQ) ${ }^{19}$ prior to initiating opioid therapy in order to stratify level of risk, and engaging in sound and ethical urine drug testing practices with all patients receiving opioids. If the resources were to be made available, it would be beneficial for each state's medical society to periodically review the risk mitigation platform of each prescribing provider and oversee any necessary improvements. It would also likely be helpful if the myriad states that currently have voluntary prescription monitoring programs changed their statuses to mandatory. Clearly, state agencies have the potential to work with physicians and their patients with pain as opposed to against them. While the FDA has been making an effort to deal with the complex opioid conundrum in an objective and productive manner, the Drug Enforcement Administration (DEA), on the other hand, seems to be dealing with the American opioid crisis through sweeping actions and reactions that have been unmethodical and lacking in forethought - and are accordingly indirectly resulting in considerable suffering - to the practices of many well-intentioned physicians, and, more tragically, to the well-being of patients.

Once the DEA begins to function as it is designed to function in regard to opioids - ie, in the best interest of the people - steps toward the resolution of our opioid crisis can potentially begin to be made. The media certainly appears to have a reciprocal relationship with the DEA, as it appears to be fixated on the regulatory agency's war on opioids and in doing so, may indirectly be fueling it. And finally, as mentioned previously, the insurance industry's obsession with cost-containment and profitability is making it impossible for many Americans to gain access to the opioids that are least likely to be abused and diverted. Physicians have more confidence in the safety of abuse-deterrent formulations, ${ }^{20}$ and may very well be choosing not to prescribe any opioids to their patients with pain when abuse-deterrent formulations are not covered by their patients' insurance.

We are certainly not advocating that all patients with pain should be utilizing opioids. Their potentially deadly iatrogeneses as well as their potential for abuse and diversion should not be underestimated. However, we will continue to posit that a carefully selected subpopulation of patients with pain for whom no other viable treatment options are available has the right to relief and enhanced quality of life - which opioids may provide. We are not denying that opiophilia had been out of hand for too many years in the US. However, the pendulum has indeed swung awry, which has benefited neither patients with pain nor society as a whole. Until patient advocacy groups are heard and clinicians of variable disciplines work in concert with regulatory agencies in the absence of media hysteria, the critical state of American pain medicine is not likely to improve. Undoubtedly, the media and the insurance industry are complicit in this unfortunate turn of events. However, as a government agency entrusted with safeguarding the well-being of Americans (as opposed to merely generating profits), we hope that the DEA will begin to monitor its policies more closely and exercise improved forethought in an effort to protect the fundamental human right to relief of pain. Let the pendulum rest, as achieving rapprochement in regard to opioid analgesics is more productive than is our recent climate of extremism.

\section{Disclosure}

This editorial is the sole opinion of the authors and does not reflect the opinion of employers, employee affiliates, and/or pharmaceutical companies listed. It was not prepared as part of Drs Fudin and Atkinson's official government duties as Clinical Pharmacy Specialists. The authors declare no other conflicts of interest in this work.

\section{References}

1. Joint Commission on Accreditation of Healthcare Organizations Comprehensive Accreditation Manual for Ambulatory Care. Oakbrook Terrace, IL: Joint Commission on Accreditation of Healthcare Organizations; 2006.

2. US. Department of Health and Human Services National Institutes of Health. NIH News. Analysis of opioid prescription practices finds areas of concern. Available from: http://www.nih.gov/news/health/apr2011/ nida-05.htm. Accessed March 1, 2014. 
3. Jones CM, Mack KA, Paulozzi LJ. Pharmaceutical overdose deaths, United States, 2010. JAMA. 2013;309(7):657-659.

4. Walwyn WM, Miotto KA, Evans CJ. Opioid pharmaceuticals and addiction: the issues, and research directions seeking solutions. Drug Alcohol Depend. 2010;108(3):156-165.

5. Federation of State Medical Boards of the United States, Inc. Model policy for the use of controlled substances for the treatment of pain. J Pain Palliat Care Pharmacother. 2005;19(2):73-78.

6. Salinas GD, Robinson CO, Abdolrasulnia M. Primary care physician attitudes and perceptions of the impact of FDA-proposed REMS policy on prescription of extended-release and long-acting opioids. J Pain Res. 2012;5:363-369.

7. United States Food and Drug Administration. FDA/CDER Response to Physicians for Responsible Opioid Prescribing Partial Petition Approval and Denial. Available from: http://www.regulations. gov/\#!documentDetail;D=FDA-2012-P-0818-0793. Accessed March 1, 2014.

8. Schatman ME. Interdisciplinary chronic pain management: international perspectives. Pain: Clinical Updates. 2012;20(7):1-5.

9. Passik SD. Tamper-resistant opioid formulations in the treatment of acute pain. Adv Ther. 2014;31(3):264-275.

10. Fudin J, Atkinson T. Opioid prescribing levels off, but is less really more? Pain Med. 2014;15(2):184-187.

11. Institute of Medicine of the National Academies. Relieving Pain in America: A Blueprint for Transforming Prevention, Care, Education, and Research. Washington, DC: National Academies Press (US); 2011.

12. Martin TW. Making the 'Pharmacy Crawl'. Wall Street Journal. September 26, 2012. Available from: http://online.wsj.com/news/ articles/SB10000872396390443720204578004873138298306. Accessed March 10, 2014.
13. Acker C. Opium: US. Overview. In: Korsmeyer P, Kranzler H, editors. Encyclopedia of Drugs, Alcohol, and Addictive Behavior. 3rd ed. New York, NY: Macmillan Reference USA; 2009:183-189.

14. Kandall S. Substance and Shadow: Women and Addiction in the United States. Cambridge, MA: Harvard University Press; 1996.

15. Schatman ME. The role of the health insurance industry in perpetuating suboptimal pain management: ethical implications. Pain Med. 2011;12: 415-426.

16. Fishbain DA, Cole B, Lewis J, Rosomoff HL, Rosomoff RS. What percentage of chronic nonmalignant pain patients exposed to chronic opioid analgesic therapy develop abuse/addiction and/or aberrant drugrelated behaviors? A structured evidence-based review. Pain Med. 2008;9(4):444-459.

17. Noble M, Treadwell JR, Tregear SJ, et al. Long-term opioid management for chronic noncancer pain. Cochrane Database Syst Rev. 2010;(1):CD006605.

18. Akbik H, Butler SF, Budman SH, et al. Validation and clinical application of the Screener and Opioid Assessment for patients with pain (SOAPP). J Pain Sym Manage. 2006;32:287-293.

19. Adams LL, Gatchel RJ, Robinson RC, et al. Development of a self-report screening instrument for assessing potential opioid medication misuse in chronic pain patients. J Pain Symptom Manage. 2004;27:440-459.

20. Wilson HD, Dansie EJ, Kim MS, Moskovitz BL, Chow W, Turk DC. Clinicians' attitudes and beliefs about opioids survey (CAOS): instrument development and results of a national physician survey. J Pain. 2013;14(6):613-627.
Journal of Pain Research

\section{Publish your work in this journal}

The Journal of Pain Research is an international, peer-reviewed, open access, online journal that welcomes laboratory and clinical findings in the fields of pain research and the prevention and management of pain. Original research, reviews, symposium reports, hypothesis formation and commentaries are all considered for publication.

\section{Dovepress}

The manuscript management system is completely online and includes a very quick and fair peer-review system, which is all easy to use. Visit http://www.dovepress.com/testimonials.php to read real quotes from published authors. 